Dicle University Journal of Engineering (DUJE)

web: http://dergipark.gov.tr/dumf

Derleme Makalesi / Review Article

\title{
Karayolu ve Demiryolu Dâhilinde Köprü Tasarımının İncelenmesi
}

\section{A Review of Bridge Desing on the Context of Highway and Railway}

\author{
Mehmet Çağrı Kızıltaş ${ }^{{ }^{*}}$ \\ ${ }^{l}$ İstanbul Ticaret Üniversitesi, İnşaat Mühendisliği Bölümü, İstanbul, mckiziltas@ticaret.edu.tr
}

\begin{tabular}{|c|c|}
\hline MAKALE BİLGILERİ & ÖZET \\
\hline $\begin{array}{l}\text { Makale geçmişi: } \\
\text { Geliş: } 26 \text { Şubat } 2020 \\
\text { Düzeltme: } 10 \text { Eylül } 2020 \\
\text { Kabul: } 15 \text { Eylül } 2020\end{array}$ & \multirow[t]{3}{*}{$\begin{array}{l}\text { Bu çalışmada ilk olarak ulaştırmadaki küresel eğilimlere değinilmiş olup ardından karayolu ve otomobil } \\
\text { kullanmına olan yönelim küresel örneklerle açıllanmıştır. Ardından ise kentsel büyümenin raylı sistemlerle } \\
\text { bağlantısı tartısıllmıştır. Sonrasında karayolu ve demiryolu sanat yapısı olarak köprüler ve tasarımları detayl olarak } \\
\text { tahlil edilmiştir. Bu kapsamda Türkiye'den köprü örnekleri paylaşılmıştı. Son olarak da sonuç ve öneriler } \\
\text { verilmiştir. }\end{array}$} \\
\hline Anahtar kelimeler: & \\
\hline $\begin{array}{l}\text { Karayolu, demiryolu, köprü } \\
\text { tasarmm, dayantm }\end{array}$ & \\
\hline
\end{tabular}

Doi: $10.24012 /$ dumf.695109

\begin{tabular}{ll}
\hline ARTICLE INFO & ABSTRACT \\
\cline { 1 - 1 } Article history: & $\begin{array}{l}\text { In this study, fistly transportation trends are mentioned and trends to highway transportation and automobile usage } \\
\text { are expressed by examples. Then connection between urban sprawl and railways is evaluated. After these bridges } \\
\text { and their designs are analyzed in deatail as an artificial structure of railways and highways. In this context bridge } \\
\text { samples by Turkey are shared. Lastly conclusions and recommendations are given. }\end{array}$ \\
$\begin{array}{l}\text { Received: } 26 \text { February } 2020 \\
\text { Accepted: } 15 \text { September } 2020\end{array}$ & \\
$\begin{array}{l}\text { Keywords: } \\
\text { Highway, railway, bridge }\end{array}$ & \\
\hline
\end{tabular}

\footnotetext{
* Sorumlu yazar / Correspondence

Mehmet Çağrı KIZILTAŞ
}

$\triangle$ mckiziltas@ticaret.edu.tr 


\section{Giriș}

Ulaştırma, sosyal-politik-teknik-ekonomikkültürel bağlantıların odağında yer alan, birbiri ile etkileştiren unsurlardan birisidir bu söz konusu unsurların her birisiyle doğrudan ve karşılıklı bir bağlantıya sahiptir. Ulaştırma, planlama ile beraber tüm söz konusu bu unsurlarin hem etkileyeni ve hem de etkilenenidir. Ulaștrma ve planlamayı, belirli bir coğrafya üzerinde izler, tasarım, planlama ve projeksiyonların tamamı olarak anlamak da mümkündür. Söz konuau coğrafya, bazen bir kent-yöre-ülke, bazen bir bölge ve bazen küresel ölçeğin tamamı olarak da telakki edilebilir. Ulaştrma ayrıca nerede ise her sektördeki arz talep dengesine bir yönüyle dahil olan bir sektörü ortaya koymaktadır, dolayısı ile de küre ölçeğindeki ilişkilerin devamlı arttığı bir yüzyılda büyük öneme sahip olmaktadır.

Geneli itibariyle dünyada Kuzey kentleri; daha az nüfus yoğun yapıları, göç yolları üzerinde olmamaları gibi konumlanmaları itibariyle ve kuzeybatı coğrafyasının yeryüzünde yakaladığı ekonomik-teknik-kültürel üstünlük çerçevesinde 'sorunlarını minimize etmede' daha avantajlı konumdadırlar. Bir başka; Anglo-Sakson (Kuzey-Batı İttifakı) kültürü şehri örneği ise dünyanın en güney ucundaki Avustralya'nın Sidney, Canberra (Kanbera) ve Yeni Zelanda'nın Wellington (Velingtın) şehirlerinde görülebilmektedir. $\mathrm{Bu}$ şehirlerde; alışılmışın dışındaki iklimleri, yüksek hayat standartları, az nüfuslanmaları itibariyle yine bir Batı Uygarlığ ortak dilinin örneklerini sunmaktadır. Türkiye; coğrafi konumu itibariyle tam bir doğal kavşak nitelemesinin içini doldurmaktadır. Yakın zamana kadar politik kültürde bu köprü olarak ifade edilmektedir. Bu nitelemelerin sosyalsiyasal kavramsallaştırması ayrı ve önemli bir konu olmakla beraber, kesin olan şudur ki doğal bir yoğunluk ve akış güzergâhı olan Türkiye coğrafyasının arz-talep dengesinin iyi yönetilmesi ve yönlendirilmesi, bir toplanmadağılma noktası olarak yeniden tasarımı, her anlamda iyi bir ulaştırma mühendisliği gerektirmektedir. Türkiye; dünyanın kültür coğrafyasının merkezinde bir konuma sahip olup, Akdeniz Havzası'nın ve aynı anda birçok beşeri havzanın önemli bir bileşenidir [1].

İçerisinde bulunduğumuz coğrafya, Kafkasya, Balkanlar, Ortadoğu, Kuzey Afrika ve İç Asya'nın komşuluğunda ve tamda merkezindedir. Bunu ifade eden yakın dönemdeki politik dil ise; 'Almanya'dan Moskova'ya Pekin'e Yeni Delhi'ye kadar bir sınırın komşuluğunda olan geniş beșeri coğrafyanın en büyük ekonomisi olma' hedefidir. Bu merkezi konum bile; bizlere tek başına 'ekonomi-politika-toplumsallık-kültür' kavramlarını hatırlatmaktadır. $\mathrm{Bu}$ ana kavramların hepsiyle ilişkili olan ise ulaştırmanın yönetimi ve şehirleşmedir.

Çin kentleri yeni karayolu ağı altyapısına büyük miktarlarda yatırım harcamaları yapmasına karşın, özellikle en büyük kentler başta olmaz üzere, henüz halen ulaştırma talebinin hızlı artışını karşılayabilecek düzeye ulaşmamıștır. Çin'e has bir problem ise yerel yolların yenilenmesi yönündeki ihtiyaca karşın, hemen hemen bütün yeni karayolu inşalarının kentin ana arterleri ve otoyollara odaklanmış olmasıdır. Örneğin Pekin ve Şanghay günümüzde yüksek kaliteli ve oldukça gelişmiş otoyol ağlarına sahiptir fakat yerel yolları halen dar ve kronik trafik tıkanıklığı problemleriyle boğuşmaktadır. $\mathrm{Bu}$ durumda, yeni inşa edilmiş ana arterlerdeki trafik, yerel yollara etkin bir şekilde dağıtılamamaktadır. Çin'deki önemli bir faktör ise, en çok araca sahip en refah seviyesi yüksek hane halklarının trafik tıkanıklığının en çok olduğu kent merkezlerinde yaşıyor olmasıdır. $\mathrm{Bu}$; araç kullanımının, alanın en yetersiz olduğu yerde en yüksek olduğu anlamına gelmektedir. Kent içi seyahat talebi aynı zamanda, çekirdekte yüksek istihdam yoğunluğuyla, Çin kentlerinin tek merkezli arazi kullanım unsuruna da bağlıdır [2].

Her iki ülkedeki iki tekerlekli motorlu taşıt sayıları kıyaslandığında ise, Çin'in Hindistan'1 2000 yılı itibariyle geride biraktığ 1 görülmekte olup bunun nedeni muhtemelen ekonomik büyüme hızının nispeten daha yüksek olmasıdır. Nispeten daha düşük gelirli olan Çin'in 
kuzeyindeki kentlerde motosiklet kullanımına getirilen keskin kısıtlamalara bağlı olarak, bu kentlerdeki motosiklet kullanım oranları ülkenin güneyindeki kentlere nazaran oldukça düşük düzeylerde kalmıştır. Örneğin; Pekin, Tianjin ve Hangzhou gibi kentlerde motosiklet modal pay1 \%2'lerin altında iken Fuzhou ve Guangzhou gibi kentlerde ise motosiklet modal payları \%10'ların üzerinde gerçekleşmektedir. Her iki ülkede de mevcut durumda motorlu iki tekerlekliler toplam motorlu taşıtlar içerisindeki en kalabalık grupları teşkil etmektedir. İki tekerlekliler orta sınıf için artan bir şekilde ekonomik olarak makul, esnek ve nispeten hızlı ulaşım imkânı sağlarken, trafik güvenliği anlamındaysa ciddi problemler teşkil etmektedirler. Aslında motosikletlerden kaynaklı yüksek ölüm oranları ve hava kirliliğine bağlı olarak, yakın dönemde çoğu Çin kenti motosiklet kullanımını ya tamamen kısıtlamış ya da kullanımlarını belli koşullar atlında kısıtlamıştır. Bu kısıtlamalar muhtemelen Çin'de gelecekteki motosiklet kullanımını azaltacaktır. Motosikletler üzerindeki bu kısıtlamalara bağlı olarak, ağırlıkları $40 \mathrm{~kg}$ 'dan az olması ve 20 $\mathrm{km} / \mathrm{saat}$ 'ten düşük tasarım hızları nedeniyle birçok kentin elektrikli bisikletlere izin vermesinden dolayı elektrikli bisikletler ve mobiletlerin satışında yakın gelecekte bir patlama beklenmektedir. 2005 yılında Çin'de yaklaşık 10 milyon elektrikli motosiklet ve mobilet satılmış olup 2006 yılında bu satışlar 16 milyona yükselmiştir. Eğer söz konusu politikalar aynı kalırsa, elektrikli bisiklet ve mobilet satış rakamları takip eden yıllarda dramatik artışlar göstermeye devam edecektir. Fakat bazı kentler, kentsel yollarda sebep oldukları trafik tıkanıklıkları ve trafik güvenliği problemleri nedeniyle çoktan elektrikli bisiklet kullanımına kısıtlar getirmeye başlamışlardır. Örneğin Guangzhou kenti 1 Aralık 2006 tarihinden itibaren bütün elektrikli bisikletleri, mobiletleri ve motosikletleri yasaklamıştır. Yakın dönem çalışmaların çoğunda motosikletler ve mobiletler motorlu taşıt kapsamında sayılıyor olmalarına karşın, dünya genelindeki farkındalık ise son yirmi yılda hızlı bir artış gösteren otomobil sahipliğine odaklanmaktadır. 1991'den
2003 y1lına kadar olan dönemde, Çin'de bin kişi başına düşen araç sayısı sadece 12 yılda beş kat artarken, aynı dönemde Hindistan'da ise bu sayı iki kattan fazla bir artış göstermiştir. Çin'de araç sahipliği oranındaki artış hızı daha yüksek olup 1998 yılı itibariyle Hindistan'1 geride bırakmış, bu aynı zamanda Çin'in kişi başı milli gelirinin Hindistan'1 geride bıraktığı yıldır. Araç sahipliği Çin ve Hindistan'in ekonomik ve politik üst tabakasında yoğunlaşmakta olup diğer taraftan orta sınıflarda da hızlı bir artış göstermekte, bunun bir nedeni de her iki ülkede de otomobil sahibi olmanın popüler bir tüketim aracı ve prestij sembolü olmasıdır [2].

Hem Çin ve hem de Hindistan kentlerindeki karayolu ağı arzı, Avrupa ve Amerika Birleşik Devletleri'nin çok gerisindedir. Örneğin ortalama karayolu ağı yoğunluğu Pekin'de 3,16 $\mathrm{km} / \mathrm{km}^{2}$ iken Şangay'da ise $4,42 \mathrm{~km} / \mathrm{km}^{2}$ 'dir olup bu oranlar Los Angeles $\left(9,00 \mathrm{~km} / \mathrm{km}^{2}\right)$ ve Londra' dakinin $\left(10,70 \mathrm{~km} / \mathrm{km}^{2}\right)$ yarısından azına tekabül etmektedir. Karayollarınca işgal edilen toplam arazi yüzölçümü yüzdesi üzerinden karayolu arzı ölçüldüğünde, Hindistan kentlerinde oldukça değişken sonuçlar elde edilmiş olup bu oran Delhi için \%21 iken Mumbayi'de ise $\% 11$ ve Kalküta'da sadece $\% 5$ olarak ölçülmüştür. Delhi bu noktada bir istisna olarak değerlendirilmektedir. Bununla beraber ulusal başkent olarak büyük merkezi hükümet yardımları sayesinde Hindistan kentleri içerisindeki en iyi karayolu ağına sahiptir [3].

Bir diğer önemli trafik tıkanıklığı kaynağı ise farklı ve karma ulaştırma mod kullanımlarının kısıtlı karayolu ağ kapasitesiyle sınırlandırılıyor olmasıdır. Özellikle Hindistan'da; bisiklet, bisikletli triportör, fayton benzerin hayvan çekişli araçlar ve yayalar gibi motorlu olmayan ulaştırma modları belirgin bir şekilde arabalar, kamyonlar, otobüsler, triportörler ve motosikletlere nazaran oldukça yavaştır. Böylesine geniş bir karayolu ağı kullanıcı çeşitliliği, aynı zamanda söz konusu farklı modların, bir dizi zorluğa neden olan bir şekilde, büyüklük, manevra kabiliyeti, kapasite, hız ve diğer işletim karakteristikleri gibi bir dizi 
farkl11ıklarından ötürü trafik güvenliği problemlerine de neden olmaktadır. Söz konusu durum Çin'de de çok farklı değildir. Bunun nedeni ise ana yollarda yolun sağ şeritlerinin yerleşmiş ve gelişmiş bir şekilde bisikletlilere ve yayalara ayrılıyor olmasıdır. Çin'de hatta bununla birlikte, ülkede sayıları hayli fazla olan bisikletliler, dönüşlerde motosikletlilerin şeridine geçiş yapma durumunda oldukları, kavşaklar başta olmak üzere yolun pek çok kesiminde motosikletliler başta olmak üzere farklı ulaştırma modlarıyla rekabete girmek durumunda kalmaktadirlar. Bu durum hem trafik tıkanıklıklarına ve hem de çarpışmalara neden olmaktadır. Ayrıca Çin kentlerindeki çoğu eski ve dar yerel yollar yayalar ve bisikletlilere özel ayrılacak düzeyde yeterli sağ şerit imkânlarına sahip olmamaktadırlar. Hindistan kentlerinde olduğu gibi, bu durum onları yolu motorlu taşıtlarla karma kullanıma zorlamaktadır [4].

\section{Materyal ve Yöntem}

Hızla artan talebe karşılık çoğu Çin kenti özellikle yeni ve geliştirilmiş raylı sistem hizmetleri başta olmak üzere toplu ulaştırma sistemlerine yoğun bir şekilde yatırım yapmaktadır. Altı kent (Pekin, Şangay, Guangzhou, Tianjin, Shenzhen ve Nanjing) metro sistemlerine sahiptir ve bu kentlerde mevcut 206 hat $\mathrm{km}$ metroya ilaveten 406 hat km daha tamamlanarak işletime alınmaktadır. Bütün bunlara ilaveten on kentte daha yeni metro sistemleri planlanmaktadır. Yedi Çin kenti ise hâlihazırda kent içi raylı sistemlere sahip olup bunlar Pekin, Şanghay, Tianjin, Chongqing, Wuhan, Dalyan ve Changchun olup diğer dokuz kentte de kent içi raylı sistemler planlanmaktadır. Son dönemlerdeki teşvikler daha ziyade raylı sistemlere yönelik olurken Çin kentlerinin büyük çoğunluğunda toplu taşıma otobüslerle gerçekleştirilmektedir. Doğrusu Çin'de 19852003 y1llar1 periyodunda otobüs say1s1 altı kat artarak 45.100'den 264.300'e yükselmiştir. 1995-2003 yılları periyodunda ise otobüs sayıları, Pekin'de dörde, Tianjin'de üçe ve Şangay'da ise ikiye katlamıştır. Bu durumda hem raylı sistem ve hem de otobüs hizmetlerinin arzı artan talepleri karşılamak için son yirmi yılda büyük bir artış göstermiştir [5].

Son birkaç yılda, bununla birlikte Çin kentleri, metro ve hafif raylı sistemlerinin geliştirilmesi, uzatılması ve inșasında büyük bir miktarı teşkil edecek bir şekilde, raylı sistem hizmetlerine odaklanmıştır. 2001'den beri raylı taşıma sistemi yatırımları Pekin'de ortalama yaklaşık 1 milyar ABD doları/yıl ve Şanghay'da da ortalama 1,7 milyar ABD doları/yıl olarak gerçekleşmektedir. Yüksek kapasiteli demiryolu taşımacılığının; Çin'in hızla gelişen kentlerini her geçen gün daha çok karakterize eden yüksek yoğunluklu ve oldukça tıkanık koridorlar boyunca çok büyük sayılardaki yolcu hareketleri için gerekliliği noktasında küçük bir soru işareti olabilir. Bazı durumlarda, bununla beraber, yüksek profilli raylı sistem projeleri otobüsler yerine tercih edilmektedir çünkü demiryolu modernite ve ileri teknolojiyi temsil etmekte ve politikacılara destekçileri ve dünyanın geri kalanına, somut ve yüksek görünürlüklü bir etki bırakma imkânı sağlamaktadır.

Fon eksikliklerine karşın, Delhi ve Kalküta'daki metro sistemleri büyümekte ve büyük kentlerdeki banliyö raylı sistemleri; ilave daha fazla tren ve yeni vagonlarla birlikte yerel trafiğgi ekspres trafikten ayırmak için bazı hat uzantılarında rayların iki katına çıkarılması ve güzergah genişletilmesiyle geliştirilmektedir. Bununla birlikte bütün bu gelişimler 1980'den bu yana üç kat artan banliyö raylı sistem talebini karşılama noktasında yetersiz kalmaktadır. Hatta problemler Hindistan'da toplu taşıma yolculuklarının kabaca \%90'ından fazlasının gerçekleştiği otobüs hizmetleri için daha da kötülemektedir. Hindistan'daki otobüslerin çoğu kötü tasarlanmış, eski, yeterince bakımdan geçmemiş olup pik (zirve) saatler boyunca kapasite aşımlı dolu olmaktadır. Hükümetin hemen her kademesi otobüs hizmetlerini ihmal etmiş olup bu hizmetlere özel şerit ayrılması ve trafikte öncelik sağlanması noktasında başarısız olmuş olup filolarını modernize edecek fonlardan da mahrum bırakmıştır [6].

Raylı sistem hizmetlerinde kayda değer gelişimler kaydedilirken, otobüs hizmetleri kötüleşmeye devam etmekte olup bu durum da 
yolcuların çoğunu otomobil ya da motosiklet gibi daha hızlı motorlu taşıtları tercih etmeye zorlamaktadir [6].

Raylı sistemlerdeki küresel artış eğilimleri ve bunun Türkiye'deki daha fa hacimli ve hızlı yansımaları neticesinde, sağlam ve işlevsel köprülerinin inşası hususu ülkemizde demiryollarını da kapsayacak şekilde artan bir ihtiyaç alanına iaşret eder bir hal alacaktır. Özellikle yüksek hızlı tren köprüleri bunun içerisinde önemli bir yeri ihtiva etmektedir. Türkiye'de günümüze kadar birçok önemli, dayanımı yüksek ve işlevsel köprünün varlığından söz edilebilir.

\section{Türkiye’den Örnekler}

\section{Ortaköy Köprüsü}

Giresun'daki Gülburnu Köprüsü, Malatya'daki Beylerbeyi Köprüsü ile Artvin'deki Akarşın Viyadükü ve Ortaköy Köprüsü kısmi beton köprülere örnek olarak verilebilir. İki şeritli 12 metre genişlikli Ortaköy Viyadükü Artvin ve Erzurum kentlerini birbirine bağlamakta olup iki eşit açıklık dâhilinde toplamda 156 metre uzunluğa sahiptir. Yarı parabolik bir şekilde kesit derinliği ayaklardan birleşim elemanlarına doğru azalmaktadır. Ayak ve birleşim elemanına yakın olanı hariç kesitin tipik uzunluğu 4,5 metre civarındadir.

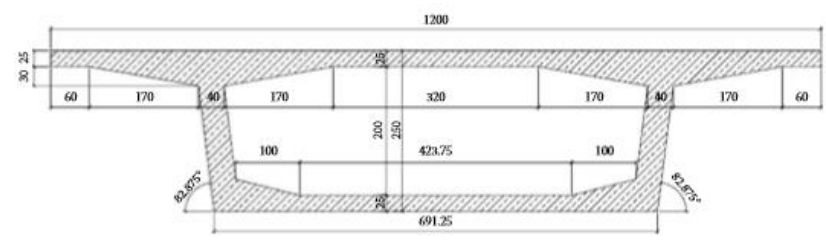

\section{Şekil 1: Birleşim Elemanındaki Kiriş Kesiti [7]}

Seçili bir köprü plan ve kesimi için zamana bağ 1 etkileri de içeren bir inşa aşaması analizi, bir bilgisayar modeli (LARSA 4D) kullanılarak icra edilmiştir. Her bir kesimin inşası tipik bir 7 gün döngüsüne sahiptir. Tipik bir 7 gün döngüsünde 90 tonluk bir transbordör formu yeni konumuna taşınmış ve beton dökülüp kirişler yüklendikten sonra döngü tamamlanmıştır. İlk tasarımda yapılan değerlendirme nihai tasarım aşamasında küçük değişimler olacak şekilde belirlenmiştir. Sütun kesimi üzerinde her birisi 19 kirişe sahip olan 44 boru kesit kullanılmıştır. Konsol inşası, mesnede hemen hemen düz konumda ulaşmaktadır. Asal gerilmeler profillerde büyük bir çatlak olup olmadığının belirlenmesi için profillerde kontrol edilmektedir [7].

Köprü; ASSHTO LRFD (2007) ve CEB-FIB (Avrupa Uluslararası Beton Komitesi Uluslararası Öngerme Federasyonu) şartnamelerinin minimum gereksinimlerine dayalı olarak tasarlanmıştır. Köprü HS30-24 yük kamyonlarına göre tasarlanmıştır. Kutu kesitin enine tasarımı, enine ilave gerilmenin, köprünün ve uzun vadeli performansin mukavemetini etkileyebilen üst başlıktaki çatlakların minimize edilmesine gerek duyulduğunu ortaya çıkarmıştır.

Üst başlıktaki enine ilave gerilme gereksinimi hareketli yük ve isı analizi vasitası ile belirlenmektedir. Profiller arası mesafe ve hareketli yükün büyüklüğü enine ilave gerilmelerin tasarımındaki belirleyici unsurları teşkil etmektedir [8].

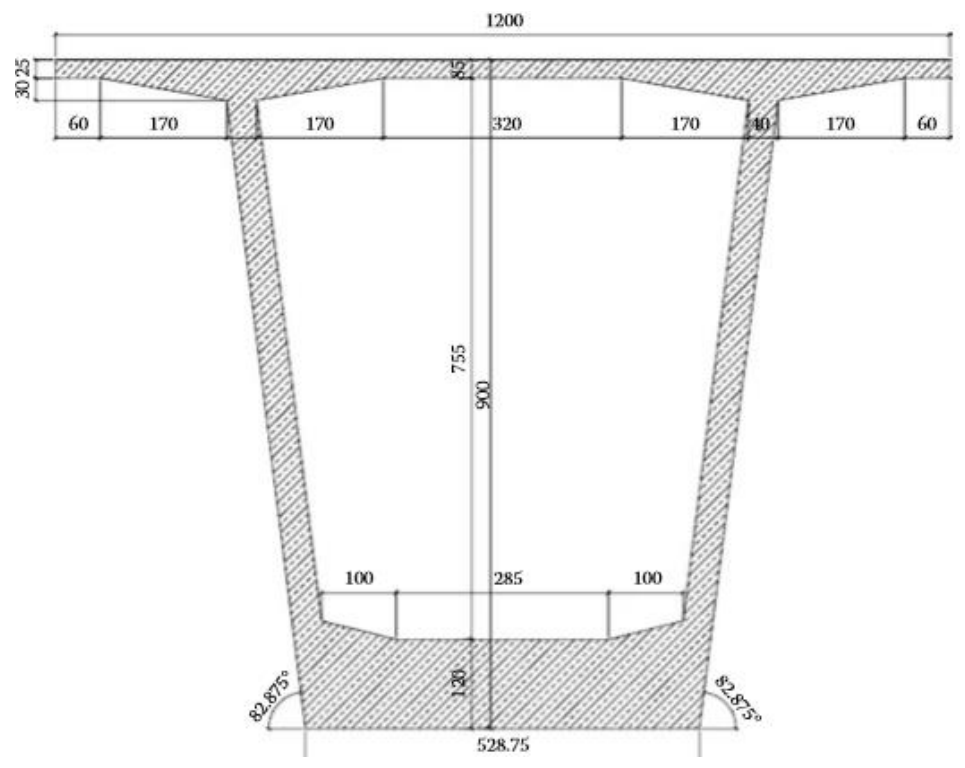

Şekil 2: Ayaktaki Kiriş Kesiti [9]

\section{Ayvacık Eynel Kemer Köprüsü}

Köprü baraj vasıtası ile birbirinden ayrılan köyleri birbirine bağlamaktadır. Köprünün toplam uzunluğu 366 metre olup bunun 160 metre uzunluğu ana açıklıktır. Çelik kemer, dâhili takviyeler dâhilinde kutu formludur. Köprünün toplam genişliği 12 metre olup 2 şerit ve 2 yaya yolundan oluşmaktadır. Araç hareketli yükü HS20-S16 olarak seçilmiş olup bu değer; 
otoyollarda kullanılan araç tasarım hareketli yükünden daha yüksektir.

Köprü AASHTO standartlarının (2002) minimum gereksinimlerine göre tasarlanmıştır. Köprünün yorulma ömrü aynı zamanda araç hareketlerinin toplam 500.000 döngüsü için hesaplama ile değerlendirilmiştir. Korozyon (çürüme) koruma ve bakım kılavuzu tasarımda yer almaktadır. İnşa boyunca su kütlesi Şekil 3'de görüldüğü üzere uzaklaştırılmıştır. Köprü tamamlanarak Mart 2009 tarihinde trafiğe açılmıştır [10].
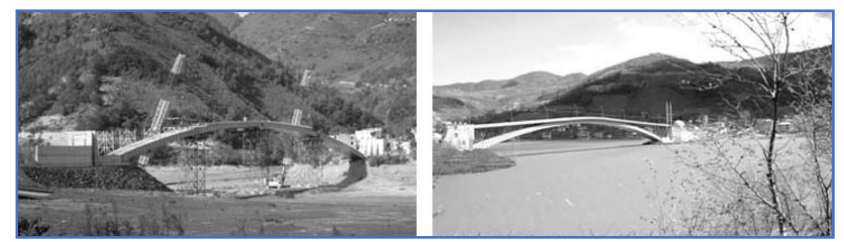

Şekil 3: İnşa Süresince ve İnşadan Sonra Samsun Ayvacık Köprüsü [10]

\section{Kablolu Yaya Köprüleri}

Türkiye'de nispeten yeni bir eğilim ise kablolu yaya köprüleridir. Köprü estetiğinin özellikle de Ankara'nın kent merkezinde çok sayıda benzer köprü inşası için birincil itici güç olduğu düşünülmektedir. Hoş mimari unsura ilave olarak orta destek ayağının çıkarılması; bir trafik kazası durumunda trafik güvenliğini arttıran bir unsur olmaktadır. Kentsel alanlar trafik tıkanıklığı problemlerine sahip olmaktadır ve yeni altgeçitler ve üstgeçitler trafik akımını daha hızlı bir hale getirir iken aynı zamanda da kentin bölgelerini hızlı akımlı trafik yolları ile bölmektedir. Bu gibi bir olay da kentte onlarca ve hatta yüzlerce yaya köprüsünün yapılmasını gerektirebilir.

Esenboğa yolunda yer alan hemen hemen tipik iki yaya yolu köprüsü Şekil 4'te görülmektedir. Kablo kuvvetlerinin ölçümü, hizmetteki köprünün doğru sehiminin tatbiki ve kablodaki kuvvet dağılımının temini için gereklidir [11]. Kablo kuvvetlerinin ölçümü tipik olarak iki tekniğin kullanımı yolu ile yapılmakta olup bunlardan birisi statik yöntem iken bu yöntemde enine doğrultuda kablo bükülmekte ve kablonun bükülmesi için uygulanan kuvvetin bir fonksiyonu olarak çekme kuvveti dolaylı bir şekilde temin edilmekte ve enine deformasyon miktarı tayin edilmektedir.

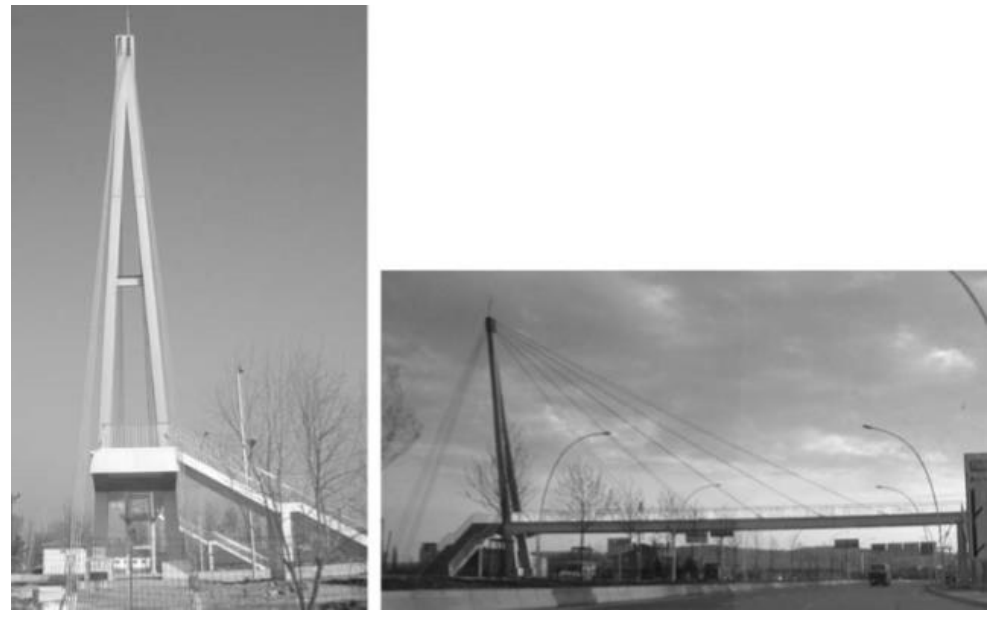

Şekil 4: Esenboğa Yolu Yaya Köprüleri Genel Görünüşü [11]

\section{Uygulama ve Başarımlar}

Yapı tasarımında aşağıdaki hususlar dikkate alınmalıdır:

- Eğimli tabliye ya da eğimli kiriş yüzeylerine bağlı etkiler

- Her bir proje için münhasıran belirlenen gereksinimlere göre gerilme artışı ya da düşüşünden kaynaklı boyuna ankraj kuvvetleri

- Her bir proje için münhasıran belirlenen gereksinimlere göre rayların kaza kayaklı kırılmalarına bağlı olarak boyuna kuvvetler

- İşletimci bileşeni tarafından belirlenen ya da UIC El Kilavuzu 779-1'de tanımlı, hat komşuluğundaki yapılarda tren geçişi kaynaklı aerodinamik ve hava akımı etkileri

- Yapıya monte edilmiş olan katener dizisi ve diğer baş üstü ekipmanından kaynaklı yükleme etkileri

- Diğer demiryolu altyapı ve ekipmanından kaynaklı yükleme etkileri

\section{Derayman (Raydan Çıkma)}

Demiryolu yapısı öyle bir şekilde tasarlanmalıdır ki bir derayman olayında, köprüdeki nihai hasar (kısmi devrilme ya da yapının bir bütün olarak çökmesi) minimum ile sınırlanmalıdır [11]. 
Bir Demiryolu Köprüsündeki Trafikte Derayman Olayl

Bir demiryolu köprüsündeki demiryolu trafiğinde derayman olayı bir kaza tasarımı durumu olarak değerlendirilmelidir. Bu noktada iki tasarım durumu hesaba katılmalıdır.

- $\quad$ Tasarım Durumu I: Bir parapet duvarı ya da mücavir hat tarafindan tutulan araçlar ile köprü tabliyesindeki ray bölgesinde geri kalan derayman olmuş araçlar dâhilindeki demiryolu araçları deraymanı durumu

- Tasarim Durumu II: Üstyap1 kenar yüklemesi (yürüme yolları gibi yapısal olmayan unsurlar hariç olmak üzere) ve köprü kenarında dengelenmiş araç deraymanı dâhilindeki demiryolu araçları deraymanı durumu

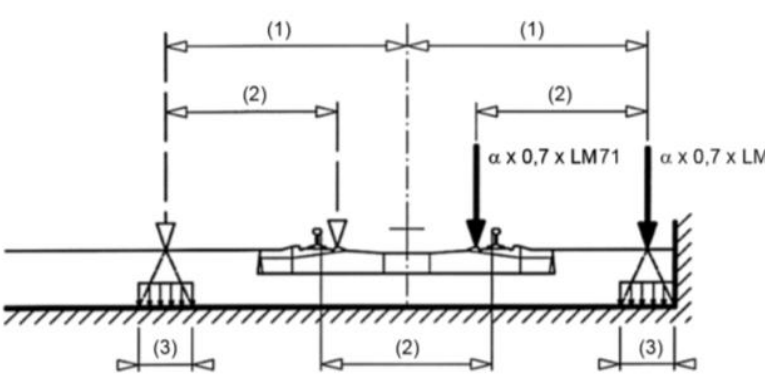

Şekil 5: Tasarım Durumu I_Q QAld ve Qald Eşdeğer Yükü [11]

Bu noktada işletmeci bileşeni ilave gereksinimler belirleyebilir. Tasarım Durumu I için yapının ana kısmının çökmesi engellenmelidir. Bununla beraber yerel hasar tolore edilebilir. İlgilenilen yapı kısmı; kaza tasarım durumunda Şekil 5 'teki tasarım yükleri için tasarlanmalıdır.

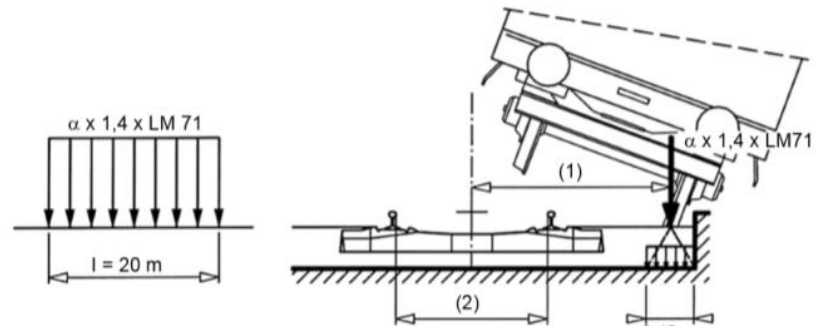

Şekil 6: Tasarım Durumu II_qA2d Eşdeğer Yükü [12]

$\alpha X 1$, 4Xyük modeli 71 (LM71); rayın merkez hattının her iki tarafinda ray gabarisinin 1,5 kat genişliğindeki bir alanın içerisinde en istenmeyen konumdaki raya paralel olmaktadır.

Tasarım Durumu II için ise köprü devrilmemeli ya da çökmemelidir. Toplam stabilitenin hesabı için QA2d=AX1, 4Xyük modeli 71 (LM71) eşitlikli yük terkibinin (dinamik faktör hariç) 20 metrelik bir maksimum toplam uzunluğunda, hesap altında yapının köşesinden üniform yayılı düşey hat yükü olarak etkidiği kabul edilmelidir.

Ayrıca kurb üzerinde yer alan köprüler için yükleme durumu ilgili bölümlerde belirlenmiş olup eğer uygulanabilir ise aynı zamanda, merkezkaç kuvveti olmaksızın dikkate alınmalıdır. Yükleme modeli 71 ve sahada 120 $\mathrm{km} /$ Saat'in üzerindeki bir maksimum hat hız için aşağıdaki durumlar dikkate alınmalıdır [12].

Durum a: Kendi dinamik faktörü ve $f=1$ ve $\mathrm{V}=120 \mathrm{~km} /$ saat için merkezkaç kuvveti dâhilinde yükleme modeli 71

Durum b: Kendi dinamik faktörü ve f azaltma faktörü için bir değer dâhilinde belirlenen bir V maksimum hızı için merkezkaç kuvveti dâhilindeki indirgenmiş yükleme modeli 71

Yükleme modeli 71 için f indirgenme faktörü şu şekilde verilmiştir.

$\mathrm{f}=[1-((\mathrm{V}-120) / 1000) \mathrm{X}((814 / \mathrm{V})+1,75)) \mathrm{X}(1-$ $\left.\left.\left(\sqrt{-} 2,88 / \sqrt{-} \mathrm{L}_{\varphi}\right)\right)\right]$

$\mathrm{f} \geq 0,35$

Burada

$\mathrm{L}_{\mathrm{f}}$ : Değerlendirmede yapısal eleman tasarımı için en elverişsiz durum olan köprülerdeki kurb raylarının yüklenmiş kısımlarının tesir uzunluğudur (metre)

\section{V: Maksimum hiz}

$\mathrm{f}=1$ için hem $\mathrm{V} \leq 120 \mathrm{~km} /$ saat ve hem de $\mathrm{L}_{\mathrm{f}} \leq 2,88$

$\mathrm{f}<1$ için hem $120<\mathrm{V} \leq 120 \mathrm{~km} / \mathrm{saat}$ ve hem de $\mathrm{L}_{\mathrm{f}}>2,88$

$\mathrm{f}_{(\mathrm{V})}=\mathrm{f}_{(300)}$ için hem $\mathrm{V}>300 \mathrm{~km} / \mathrm{saat}$ ve hem de $\mathrm{L}_{\mathrm{f}}>2,88$

$\mathrm{SW} / 2$ ve yüklemesiz tren yük modelleri için $\mathrm{f}$ indirgeme faktörü değeri 1,0 olarak alınmalıdır. 71 ve SW/0 yük modelleri için merkezkaç kuvvetleri, verili yük durumlarına göre tasnifli 
düşey yükler kullanılarak belirlenmelidir. $\mathrm{Bu}$ noktadaki kriter, $120 \mathrm{~km} / \mathrm{Saat}$ 'i aşan maksimum bir izin verilen araç hızı dahilinde ağır yük trafiği için geçerli değildir. $120 \mathrm{~km} /$ Saat'i aşan bir hız dâhilindeki ağır yük trafiği için ilave gereksinimler belirlenmelidir [13].

\section{Sürtünme ve Frenlemeye Bağll Olaylar}

Sürtünme ve frenleme kuvvetleri, hattın boyuna doğrultusunda rayların tepesinden etkimektedir. Dikkate alınan yapısal unsur için frenleme ve sürtünme etkileri adına mütekabil $\mathrm{L}_{\mathrm{a}}$, b tesir uzunluğu boyunca üniform yayılı olarak hesaba katılmalıdırlar. Frenleme ve sürtünme kuvvetlerinin doğrultusu her bir hatta kabul edilen seyahat doğrultusunda hesaba katılmalıdır. Sürtünme ve frenleme kuvvetlerinin karakteristik değerleri aşağıdaki gibi alınmalıdır:

Sürtünme Kuvveti: 71, SW/0, SW/2 ve HSLM (yüksek hız yük modeli_YHYM) yük modelleri için

$$
\mathrm{Q}_{\text {lak }}=33 \mathrm{kN} / \mathrm{m} * \mathrm{~L}_{\mathrm{ab}}(\text { metre }) \leq 1000 \mathrm{kN}
$$

Frenleme Kuvveti: 71, SW/0, SW/2 ve HSLM (yüksek hız yük modeli_YHYM) yük modelleri için

$\mathrm{Q}_{\mathrm{lbk}}=20 \mathrm{kN} / \mathrm{m} * \mathrm{~L}_{\mathrm{ab}}($ metre $) \leq 6000 \mathrm{kN}$

$\mathrm{SW} / 2$ yük modeli için

$\mathrm{Q}_{\text {lak }}=35 \mathrm{kN} / \mathrm{m} * \mathrm{~L}_{\mathrm{ab}}$ (metre)

Sürtünme ve frenleme kuvvetlerinin karakteristik değerleri, ilgili şartnamede ifade edilen $\mathrm{f}$ katsayısı ya da $\varphi$ katsayısı ile çarpılmamalıdır. $\mathrm{SW} / 0$ ve $\mathrm{SW} / 2$ yük modelleri için frenleme ve sürtünme kuvvetlerinin sadece ilgili noktalara göre yüklenene yapının ilgili kısımlarına uygulanması gerekmektedir. Sürtünme ve frenleme; yüklemesiz tren yükleme modeli için ise ihmal edilmelidir. Bu karakteristik değerler örneğin genleşme araçları ile birlikte ya da onlarsız bir şekilde sürekli kaynaklı raylar ya da mafsallı raylarda olduğu gibi bütün hat inşa tiplerine uygulanabilirdir. SW/0 ve 71 yükleme modelleri için sürtünme ve frenleme kuvvetleri şartnamede ilgili maddelerde belirtilen gereksinimlere göre $\alpha$ katsayısı ile çarpılmalıdır. 300 metreden fazla yükleme uzunlukları için frenleme etkilerinin değerlendirilmesinde ilave gereksinimler işletmeci tarafindan belirlenmelidir [14].

\section{Sonuçlar ve Tartışma}

Ulaştırma ekonomisi hakkında çoğu kişinin kısıtlı düzeyde bilgisi bulunmaktadır. Ancak hemen herkes; yüksek vergiler, kirlilik (gürültü, hava) olmaksızın ve diğer yol kullanıcılarıyla herhangi bir tartışma yaşamaksızın rahat, güvenli ve ekonomik bir seyahat talep etmektedir. $\mathrm{Bu}$ durum,

1. Artan motorlu taşitlarla seyahate uyarlandığında ise sürekli artan otoyol ve otopark kapasitesi ihtiyacı, ilaveten kaza riskleri, kirlilik salımları ve diğer istenmeyen etkilerin karşılanması olarak anlaşılabilir [14].

2. Ülkemiz bulunduğu coğrafyanın stratejik özelliği nedeniyle ulaşım sektöründe önemli bir yere sahiptir. Avrupa'y1 Asya'ya bağlayan, Ortadoğu'nun kilit ülkesi Türkiye, dünya ülkelerinin özellikle karadan ve denizden bağlantılarını sağlamaktadır. $\mathrm{Bu}$ durum ülkemizin önemini bir kat daha arttırmaktadır [15]. Uzun yillar sürdürülen çalışmalar sonucu ülkemizde kara, deniz ve hava ulaşımında önemli gelişmeler sağlanmış sosyal ve ekonomik kalkınmamızda sahip olduğumuz ulaşım sisteminin de önemli katkıları olmuştur [16].

3. Etkili bir denetleme ve bunun yanı sıra da 3 ve daha fazla yolculu otomobillere özel şerit ayrılması durumunda kullanıcıların tek kişili özel otomobilden belrili ölçülerde cayabileceği görülmektedir [17]. $\mathrm{Bu}$ da yaklaşık olarak \%28'lik bir değere tekabül etmektedir. Bu indirgeme oranları ise karayollarındaki yoğun trafiği pekçok önemli geçişte nispeten akıc1 trafik haline getirmeyi temin edebilir görünmektedir [18].

4. Dünyadaki sayılı örneklerden birini teşkil eden, İstanbul'daki metrobüs (BRT) uygulaması ile günde 500 araçla 1.000.000 yolcu taşınırken, buna mukabil olarak, 50.000 servis aracıyla taşınan yolcu sayıs1 2.200.000/gün'dür [19]. Özel otomobillerle ise İstanbul genelinde 
günde 1.500 .000 yolculuk yapıldığı ve bir özel otomobilde ortalama 1-1,2 yolcu olduğu düşünüldüğünde yaklaşık 1.500.000 yolcu taşınmaktadır [20].

Buradan hareketle hem metrobüs uygulamasının ve hem de toplu taşımanın, kent içi ulaşımdaki yeri ve önemi açıç̧a anlaşılmaktadır [21]. İstanbul' da kent içi yolculuklarda pik saatlerde ortalama hızın $10 \mathrm{~km} /$ Saat'e kadar düştüğü ve trafik tıkanıklığının İstanbul'a maliyetinin 6 milyar TL/yıl olduğu düşünüldügün̈de, verimli bir toplu taşıma sisteminin önemi daha da açık olarak anlaşılmaktadır [22]. Sürdürülebilirlik kavramı; kentsel dönüşümden, entegre ve dengeli bir modal karaktere sahip ulaştırma sisteminden ayrı düşünülemez. Burada sürdürülebilirlik kavramı; 'insan odaklı, tasarrufu önceleyen, üretimi karakterize eden ve tüketimi dengeleyen' bir yaklaşım olarak okunabilir ki; buda 'günümüzü aşan, ileriyi planlayan ve bunun içinde geçmişin kavrayışı üzerine ayağını yere sağlam basan' bir bakış açısını beraberinde getirir [23]. Bütün bunlarda; bir 'süreklilik algısı' gerektirir. $\mathrm{Bu}$ algıda; 'geçmişi doğru okuyan've bunun üzerine 'sürekliliği olan bir perspektifin inşası'nı bizlere işaret eder. Bütün örnek Batılı Şehirler; bu bütünlüğün, sürekliliğin ve sürdürülebilirliğin örneklerini yansıtarak kendi doğrularını ortaya koymaktadırlar. Bu gibi kararlar birçok zaman, birbiriyle çelişen amaçlar arasında önem ve öncelik sırasına göre tercihi gerektirmektedir. Örneğin, araç seyahat hızlarını arttırmaya yönelik stratejiler, çarpışma risklerini arttırabilir ve yürüyüş standartlarını düşürebilir [24].

\section{Teşekkür}

Birlikte mesai yaptığımız hocalarımıza teşekkür ederiz.

\section{Kaynaklar}

[1] Kızıltaş M., Altan M. 2017. Evaluation of Intermodal Integration on the Context of Marmaray and Bosphorus Bridges, IRF Regional Congress, Dubai.

[2] Altan M., Kızıltaş M., Ayözen Y. 2020. High Speed Railways, Current Status and Development Trends at International Scale and Turkey, İstanbul Aydın Üniversitesi, IJEMME Dergisi (yayın aşamasında)

[3] Xia C., Xia H., Roeck G. 2014. "Dynamic response of a trainbridge system under collision loads and running safety evaluation of high-speedtrains,Computers and Structures, vol. 140, pp.2338

[4] Zhou H., Ni Y., Ko J. 2010. "Constructing input to neural Networks for modeling temperature-caused modal variability: mean temperatures, effective temperatures, and principal components of temperatures," Engineering Structures, vol. 32, no.6, pp.1747-1759.

[5] Dianov V., Gevondian T. 2014. Parking system of high reliability innovation Technologies, Vol. 2. pp 531-535.

[6] Granado F., Coady D., Gillingham R. 2010, The Unequal Benefits of Fuel Subsidies: A Review of Evidence for Developing Countries, World Development Vol. 40, No. 11.

[7] Ilicali M., Catbas N., Kizilta M.s, Ongel A. 2014. Multimodal Transportation Issues in Istanbul: A Case Study for Traffic Redistribution Due to Long Span Bridge Rehabilitation, Periodical of Advanced Materials Research, Vol. 831. P.413-417.

[8] Kizıltas M., Altan M. 2018. A Review in Term of Service Parameters on the Modal Choices and Mass Transport, Izmi

[9] Altan M., Kızıltaş M. 2020. Yüksek Hızlı Demiryolları, Yolcu Ve Yük Taşımacılığı Karşılaştırmaları Bağlamında Küresel Ölçekl Bir Derleme Çalışması, Dicle Üniversitesi Mühendislik Fakültesi Dergisi, ULAKBİM (yayın aşamasında)

[10] Takagi R. 2005. High speed railways: the last 10 years, Japan Railway and Transport Review, 40, 4-7.

[11] Ebeling K. 2005. High-speed railways in Germany, Japan Railway and Transport Review, 40, 36-45

[12] Theurel J., Theurel A., Lepers R. 2012. Physiological and cognitive responses when riding an electrically assisted bicycle versus a classical bicycle. Ergonomics, 55, 773e781.

[13] Kızıltas M. 2018. Küresel Örnekleri ile Toplu Ulaștırma, Transis 2018, İstanbul Ulaşım Kongresi ve Fuarı, İstanbul, 8-10 Kasım.

[14] Kızıltaş M. 2015. Traffic Safety and Railway Applications, Transportation World Newspaper.

[15] Nijkamp P. 2009. Regional development as self-organized converging growth, In: Kochendörfer-Lucius, G., Pleskovic B. (Eds.), Spatial Disparities and Development. The World Bank, Washington DC, pp. 265-281.

[16] Geurs K., vanWee B. 2004. Accessibility evaluation of landuseand transport strategies review and research directions, Journal of Transport Geography 12, 127-140.

[17] Ureña J., Menerault P., Garmendia M. 2009. "The high-speed rail challenge for big intermediate cities: A national, regional and local perspective", Cities, 26, 5, 266-279.

[18] 10. Kalkınma Planı Ulaştırma ve Trafik Güvenliği Ö.İ.K. Raporu, 2012. Ankara

[19] Altan M., Kızıltaş M. 2018. Toplu Taşımada Çok Amaçlı Karar Verme ve Metropoliten Bir Alanda Ev-İș Ulaşım Hizmeti Modellemesi, Karaelmas Fen ve Mühendislik Dergisi, 8(1):99105.

[20] Altan M., Kızıltaș M., Ayözen Y. 2020. Comparative Evaluation of the Development, Current Situation and Investment Plans of High Speed Railways on National, Regional and International Basis, İstanbul Aydın Üniversitesi, IJEMME Dergisi (yayın aşamasında)

[21] Kızıltas M., Tekin A. 2017. İstanbul'da Raylı Sistem Hatlarının Hat ve Sefer Entegrasyonlarının İncelenmesi, Transist 2017, İstanbul Ulaşım Kongresi ve Fuarı, İstanbul, 2-4 Kasım

[22] Amendo C., Hamm P., Kelly J., Maerz L., Brunette K., Scrudato M., Finley G., Greene L. 2016. Autonomous VehiclesConsiderations for Personal and Commercial Lines Insurers. Munich Re.

[23] Sak, H., Senior, A., Beaufays, F., (2014) Long short-term memory recurrent neural network architectures for large scale acoustic modeling. INTERSPEECH, p.338-342.

[24] Langford, B., Cherry, C., Yoon, T., Worley, S., Smith, D., (2013) North America's first ebike share: a year of experience. Transport. Res. Record: J. Transport. Res. Board (In Press) 